Volume 10 - $2020 \mid$ n. 34

\title{
A relação conflituosa entre a Meta 20 do Plano Nacional de Educação (2014-2024) e a Emenda Constitucional 95/2016
}

\author{
Silvia Cristina Conde Nogueira \\ Darlyng Maria Gomes Tavares \\ Universidade Federal do Amazonas (UFAM), Manaus/AM - Brasil
}

\section{Resumo}

O artigo anuncia a incompatibilidade entre a Emenda Constitucional (EC) 95/2016 e a Meta 20 do Plano Nacional de Educação (PNE), evidenciando a disputa pelo fundo público. Analisou-se a essência histórica que contribuiu com a garantia legal de recursos educacionais relacionados ao PIB, além do contexto de aprovação da Lei do PNE 2014-2024 e da EC 95, de modo a estabelecer relação com o financiamento da educação pública e possibilitar o exame do compromisso ou descompromisso da União com o aumento de recursos, evidenciando os dados dos investimentos da União com Manutenção e Desenvolvimento do Ensino e dos Relatórios de Monitoramento das Metas do PNE publicados pelo Instituto Nacional de Estudos e Pesquisas Educacionais Anísio Teixeira. Os resultados demonstram que o Plano Nacional de Educação garante investimentos públicos em educação pública, assim como também permite que o Estado invista, inclusive, em instituições privadas. Por fim, constata-se a inviabilização da Meta 20, ao se implementar a EC 95/2016.

Palavras-chave: Plano Nacional de Educação. Emenda Constitucional 95/2016. Fundo Público. Financiamento da Educação Pública.

\section{The conflicting relationship between Goal 20 of the National Education Plan (2014-2024) and Constitutional Amendment 95/2016}

\section{Abstract}

The article announces the incompatibility between Constitutional Amendment 95/2016 and Goal 20 of the National Education Plan (PNE), highlighting the dispute over the public fund. The historical essence that contributed to the legal guarantee of educational resources related to GDP was analyzed, in addition to the context of approval of the PNE Law 2014-2024 and the Amendment 95, in order to establish a relationship with the financing of public education and make it possible to examine the Union's commitment or lack of commitment to increased resources, evidencing the data of the investments of the Union with Maintenance and Development of the Teaching and of the Reports of Monitoring of the Goals of the PNE published by the National Institute of Studies and Educational Researches Anísio Teixeira. The results show that the National Education Plan guarantees public investments in public education, as well as allowing the State to invest, even in private institutions. Finally, we found that Goal 20 is not achievable when implementing the amendment 95/2016.

Keywords: National Education Plan. Constitutional Amendment 95/2016. Public Fund. Funding of Public Education. 
A relação conflituosa entre a Meta 20 do Plano Nacional de Educação (2014-2024) e a Emenda Constitucional 95/2016

\section{Introdução}

Este artigo é um desdobramento da dissertação denominada Emenda Constitucional 95/2016: Instrumento de retomada da desvinculação das receitas da União. Surge a partir da análise das contradições da Emenda Constitucional 95, de 15 de dezembro de 2016 ${ }^{1}$, para o financiamento da Manutenção e Desenvolvimento do Ensino². Entre as contradições, manifesta-se a incompatibilidade entre a Emenda 95 e a Meta 20 da Lei 13.005, de 25 de junho de 2014, que rege o Plano Nacional de Educação (PNE), no contexto do financiamento da educação pública.

O objetivo é trazer à tona a relação entre a Meta 20 do Plano Nacional de Educação e a EC 95/2016, por meio da exposição da análise dos dados consolidados da União com a Manutenção e Desenvolvimento do Ensino e mediante os documentos publicados pelo INEP que tratam do acompanhamento da referida meta, além da verificação da função da Emenda diante desse panorama, evidenciando a disputa pelo fundo público.

De um lado, o PNE, que, entre suas exigências legais, estabelece o aumento progressivo de investimentos públicos para a educação pública, proporcional ao Produto Interno Bruto ${ }^{3}$ (PIB) (BRASIL, Lei 13005, 2014, art. 2, VIII e Meta 20). De outro, a Emenda 95 determina limites orçamentários para as despesas primárias ${ }^{4}$, incluindo os investimentos com a Manutenção e Desenvolvimento do Ensino (MDE) (BRASIL, EC 95, 2016, art. 107 e 110), implicando na redução de quantitativo dos recursos da educação pública. Ou seja, as duas leis estabelecem uma relação conflituosa.

Desse conflito, evidencia-se a disputa pelo fundo público ${ }^{5}$ da educação no eixo das políticas do Estado brasileiro. De acordo com Salvador (2012), existem disputas na sociedade capitalista pelo fundo público, especialmente no orçamento estatal, o que reflete a luta política entre diferentes interesses. Ressalta-se que o fundo público, em atendimento à legislação e aos anseios de grande parte da sociedade, deve garantir recursos suficientes para financiar políticas sociais, tais como a educação, sendo assim, também é capaz de espelhar as prioridades do governo (SALVADOR, 2012).

Assim, o percurso metodológico partiu da revisão de literatura sobre o financiamento da educação pública, com o Plano Nacional da Educação e com a Emenda Constitucional 95/2016. Além disso, realizou-se uma pesquisa documental dos seguintes documentos: dados consolidados de todos os recursos públicos da União com Manutenção e Desenvolvimento do Ensino, que constam no Relatório Resumido da Execução Orçamentária (RREO) de 2007

1 Altera o Ato das Disposições Constitucionais Transitórias, para instituir o Novo Regime Fiscal, e dá outras providências.

2 A Lei de Diretrizes e Bases da Educação Nacional de 1996 considera Manutenção e Desenvolvimento do Ensino todas as despesas executadas que atendam os objetivos da educação, tanto da educação básica, como da educação superior, conforme suas especificações no artigo 70.

3 De acordo com o Instituto Brasileiro de Geografia e Estatística (IBGE), o Produto Interno Bruto é calculado anualmente para mensurar a soma dos bens e serviços produzidos no País.

4 As despesas primárias são todos os gastos do Estado, excluindo as despesas financeiras, tais como juros e amortizações.

5 "O fundo público envolve toda a capacidade de mobilização de recursos que o Estado tem para intervir na economia, seja por meio das empresas públicas, pelo uso das suas políticas monetárias e fiscal, assim como pelo orçamento público" (SALVADOR, 2012, p. 126). 
A relação conflituosa entre a Meta 20 do Plano Nacional de Educação (2014-2024) e a Emenda Constitucional 95/2016

a 2008, publicado pelo Tesouro Nacional, com a finalidade de relacioná-lo com o Produto Interno Bruto.

Procedeu-se também uma análise dos Relatórios de Monitoramento das Metas do Plano Nacional de Educação, com o foco na implementação da meta 20 do PNE, publicados pelo Instituto Nacional de Estudos e Pesquisas Educacionais Anísio Teixeira (INEP), que, até o momento, publicou dois relatórios com a finalidade de analisar os anos de 2014 e 2015. A partir dessa análise, os dados foram cruzados para identificarmos as contradições entre a EC 95 e a meta 20 do PNE.

É certo afirmar que é necessário um esforço entre os entes federativos para aumentar os recursos da educação pública, contudo, este artigo não demonstra os dados consolidados dos estados, municípios e Distrito Federal com Manutenção e Desenvolvimento do Ensino, pois o objetivo é verificar o compromisso ou o descompromisso da União, uma vez que este ente federativo possui a maior capacidade financeira para contribuir com a educação de qualidade socialmente referenciada.

Por meio da análise dos dados quantitativos, apresenta-se o descompromisso da União com o aumento de recursos para a educação pública conforme garante a meta 20 do PNE. Por fim, revela-se que a implementação da Emenda 95/2016 já tem surtido sobre a quantidade de recursos destinados para a Manutenção e Desenvolvimento do Ensino da União.

\section{A origem da relação legal dos investimentos em educação pública com o Produto Interno Bruto}

Esta seção contextualiza o nascimento do Plano Nacional de Educação (PNE) no Brasil e a origem da necessidade de garantir-se investimentos públicos em educação relacionados ao Produto Interno Bruto (PIB). É fato que o PNE é uma bandeira levantada pela sociedade civil organizada, conduzida aos debates no cerne das políticas públicas, com a finalidade de transformá-lo em uma obrigação estatal por meio de Lei.

O Plano Nacional de Educação (PNE), em sua essência, teve seu berço com o Manifesto dos Pioneiros da Educação, assinado por diversos educadores, publicado em 1932 (SAVIANI, 2010). Saviani (2010) aponta que o Manifesto, após realizar um diagnóstico da situação da educação pública no Brasil, resultou em um "Plano de Reconstrução Educacional".

Esse plano apresentou-se como um instrumento científico para os educadores, tanto para estudos, quanto para resolver os problemas educacionais, com o propósito de evitar o espontaneísmo ou improvisações. No entanto, para o governo da época, esse Plano revestiuse em um mecanismo de controle político-ideológico da política educacional (SAVIANI, 2010).

Esse fato influenciou a Constituição Brasileira de 1934 no artigo 150, ao estabelecer que a União fixasse um Plano Nacional de Educação e ao exigir no artigo 152 que um Conselho Nacional de Educação elaborasse esse documento (SAVIANI, 1999). Com isso, o Decreto 19.850, de 11 de abril de 1931, que criou o Conselho Nacional de Educação, foi revisitado e reorganizado em 1936 e reestruturado em 1937 (SAVIANI, 1999).

Sob esse contexto, os conselheiros, orientados pelo Ministro Gustavo Capanema, elaboraram um Plano Nacional de Educação contendo 504 artigos, denominado "Código da Educação Nacional”, e encaminhado em 1937, abandonado no mesmo ano (SAVIANI, 1999), 
A relação conflituosa entre a Meta 20 do Plano Nacional de Educação (2014-2024) e a Emenda Constitucional 95/2016

por conta do golpe político que deu início ao Estado Novo, que resultou no fechamento dos poderes representativos (VIEIRA; RAMALHO; VIEIRA, 2017).

De acordo com Saviani (1999), esse projeto correspondia à Constituição Brasileira de 1934, mas se afastava das ideias do Manifesto dos Pioneiros. Essas duas visões sobre o PNE, uma de governo, outra da sociedade organizada, expressam a correlação de forças, repercutindo na primeira Lei de Diretrizes e Bases da Educação Nacional (LDBEN) (SAVIANI, 1999).

Com a promulgação da primeira LDBEN, em 1961, aprovou-se o artigo 92, que tratava das responsabilidades de todos os entes federativos com os investimentos mínimos em Manutenção e Desenvolvimento do Ensino (BRASIL, 1961; SAVIANI, 1999). O parágrafo $1^{\circ}$ desse artigo determinou que nove décimos dos recursos federais para a educação fossem divididos igualmente entre o Fundo Nacional do Ensino Primário, o Fundo Nacional do Ensino Médio e o Fundo Nacional do Ensino Superior (BRASIL, 1961; SAVIANI, 1999).

Além disso, o parágrafo $2^{\circ}$, desse mesmo artigo, endossou que o Conselho Federal de Educação seria o responsável por elaborar um "Plano de Educação" que determinasse os prazos de aplicações dos recursos em cada Fundo (BRASIL, LDBEN N 4.024, 1961). Para Saviani (1999), esse conceito de "Plano de Educação" assumiu o sentido de aplicar recursos financeiros na educação.

Em 1962, o PNE surgiu como um conjunto de regras, não como projeto de lei, que visava investimentos financeiros em educação a serem alcançadas em um prazo de oito anos (VIEIRA; RAMALHO; VIEIRA, 2017). Esse conjunto de regras fora modificado em 1964, o que resultou na retirada da responsabilidade federal, ao estabelecer Planos Regionais ao invés de continuar com um Plano Nacional, minimizando a obrigação federal com o aumento de recursos (VIEIRA; RAMALHO; VIEIRA, 2017).

Por conseguinte, entre 1986 a 1989, as políticas foram formuladas de maneira autoritária, incluindo as políticas para a educação, tais como o Plano "Educação para todos", que executou uma estratégia de repasse de recursos públicos aos estados e municípios, desconsiderando o Plano anterior (SAVIANI, 1999).

Posteriormente, durante a década de 1990, a sociedade civil organizada, com vistas para a promoção de uma educação de qualidade social no Brasil, diagnosticou a situação educacional do País, propôs diversos projetos com a finalidade de atender princípios que valorizassem o sujeito alvo da educação, reivindicando o aumento progressivo de recursos públicos para concretizar o plano (BOLLMAN, 2010).

Ao analisar os principais projetos do Fórum Nacional em Defesa da Escola Pública (FNDEP) em suas contribuições, Bollman (2010) constatou que esse movimento contribuiu para mobilizar grande parte da sociedade civil organizada pela garantia da educação pública em diversas legislações, principalmente na Constituição Federal (CF) de 1988 e na Lei de Diretrizes e Bases da Educação Nacional (LDBEN).

Entre muitas iniciativas do Fórum, cita-se o I Congresso Nacional de Educação (CONAE), que, sediado em Belo Horizonte em 1996, entre outras finalidades, pretendeu "[...] organizar a intervenção nos processos de elaboração e tramitação da LDB e sistematizar as diretrizes educacionais para a elaboração do PNE - Proposta da Sociedade Brasileira" (BOLLMAN, 2010, p. 665). 
A relação conflituosa entre a Meta 20 do Plano Nacional de Educação (2014-2024) e a Emenda Constitucional 95/2016

Com isso, em 1997, o Fórum incentivou várias atividades em todo o País, antes da realização do II CONAE, garantindo a consolidação do Plano Nacional de Educação: Proposta da Sociedade Brasileira (PNE: PSB), pautado nos princípios voltados para a promoção da igualdade, da justiça social, da concepção de ser humano, da democracia, da educação, da autonomia, da gestão da avaliação e do currículo (BOLLMAN, 2010).

Esse PNE-PSB partiu do diagnóstico das necessidades e limitações educacionais do Brasil, bem como da relação de tal entendimento com a realidade da educação de outros países (BOLLMAN, 2010). Desse relatório, o Fórum apresentou algumas propostas para o financiamento da educação (BOLLMAN, 2010). Posteriormente, o documento foi submetido como Projeto de Lei, apresentado pelo Poder Executivo em 1998, demonstrando detalhes inexistentes no projeto governamental vigente (HELENE, 2013).

Ao demonstrar os custos anuais necessários à educação, o PNE-PSB concluiu que o Estado deveria aumentar os recursos, de forma que atingisse 10\% do PIB após 10 anos (HELENE, 2013). Esse percentual contemplava a valorização dos profissionais da educação, especialmente dos professores, o número de crianças e jovens dentro da escola, de instrumentos de gratuidade, da manutenção da infraestrutura escolar, da biblioteca e de outros espaços, além dos insumos para a garantia da qualidade (HELENE, 2013).

O Congresso Nacional acabou frustrando a proposta inicial para o financiamento da educacional contida no Plano Nacional de Educação do Projeto da Sociedade Brasileira, ao aprovar o PNE de 2001-2011, por meio da Lei 10.172, de 9 de janeiro de 2001, que previa investimento público de $7 \%$ do PIB em até dez anos. No entanto, o então Presidente da República, Fernando Henrique Cardoso, em uma atitude antidemocrática e unilateral, vetou o artigo que previa a relação dos investimentos públicos em educação com o PIB (HELENE, 2013).

Nessa direção, o Projeto da Sociedade Brasileira, apesar de conseguir a discussão por vias legais, não obteve êxito em garantir, por meio da Lei, a relação dos investimentos públicos em educação com o Produto Interno Bruto. Isso pode demonstrar que a correlação de forças pelo fundo público para a educação conta com diversos desafios, sobretudo a resistência dos governos em implementar Leis que garantam um aporte de recursos suficientes para a realidade educacional.

Além disso, Amaral (2012) destaca que a relevância da educação em um país pode ser mensurada ao se considerar três indicadores concomitantemente: o primeiro seria o total de recursos aplicados relacionado ao PIB; o segundo considera as riquezas totais do país, expressos como PIB, e, finalmente, a quantidade de alunos a serem atendidos, que podem ser representados por pessoas que estejam em idade escolar, por exemplo. Ou seja, a luta da sociedade organizada não se resume, apenas, aos recursos pelos recursos, mas pelo desenvolvimento do País por meio de uma educação socialmente referenciada.

\section{Contexto do PNE (2014-2024) e da Emenda Constitucional 95/ 2016}

O contexto histórico que influenciou a aprovação da Lei do Plano Nacional de Educação (2014-2024) e da Emenda 95/2016 é essencial para explanar os avanços e os limites para o financiamento educacional público. O pressuposto é que a disputa pelo fundo público da educação é evidente nesses dois processos históricos, que agem diretamente no aporte de recursos e expressam diferentes projetos de sociedade. 
A relação conflituosa entre a Meta 20 do Plano Nacional de Educação (2014-2024) e a Emenda Constitucional 95/2016

Devido à proximidade da expiração da validade do PNE (2001-2010), as discussões sobre o veto do Presidente pela relação dos investimentos em educação com o PIB intensificaram-se com o movimento de debate do projeto que, posteriormente, se tornaria a Emenda Constitucional 59, de 11 de novembro de 2009 (AMARAL, 2012). A promulgação da Emenda 59/2009, entre outras providências, garantiu o acréscimo da seguinte redação no artigo 214 da Constituição Federal:

A lei estabelecerá o plano nacional de educação, de duração decenal, com o objetivo de articular o sistema nacional de educação em regime de colaboração e definir diretrizes, objetivos, metas e estratégias de implementação para assegurar a manutenção e desenvolvimento do ensino em seus diversos níveis, etapas e modalidades por meio de ações integradas dos poderes públicos das diferentes esferas federativas que conduzam (BRASIL, EC n 59,2009 , art. 4).

Diante desse artigo, tornou-se urgente e obrigatório um Plano Nacional de Educação que contemplasse as necessidades da educação para o período de dez anos. O objetivo constitucional revela que o PNE tem a finalidade de articular o Sistema Nacional de Educação, além de proferir as diretrizes, os objetivos, as metas e as estratégias que conduzam à Manutenção e Desenvolvimento do Ensino (MDE), na forma de Lei.

É necessário ressaltar que o PNE, apesar de ser garantido via constitucional em 2009, remonta aos anseios do Manifesto dos Pioneiros da Educação de 1932 e da Proposta da Sociedade Brasileira da década de 1990 por uma educação de qualidade social, conforme exposto na seção anterior.

Com esse artigo, a mesma Emenda que garantiu o PNE também garantiu a relação dos investimentos públicos com o Produto Interno Bruto (PIB), ao definir que, a partir da sua promulgação, os futuros Planos Nacionais de Educação (PNE) deveriam mensurar as metas de aplicações de recursos públicos proporcionais ao Produto Interno Bruto (PIB) (BRASIL, EC $\mathrm{n}^{\circ}$ 59, 2009, art. 4, VI).

Após muitos anos de intensos debates e correlação de forças, esse fato tornou-se uma vitória da sociedade civil organizada. Sobre esse contexto, é possível afirmar que, tanto o Plano Nacional de Educação como a relação dos investimentos públicos em educação, foram possíveis por meio de disputas democráticas que culminaram na garantia constitucional.

A partir desse momento, o próximo passo seria garantir, por meio do próximo Plano Nacional de Educação, os $10 \%$ exigidos na década de 1990. A partir do final do PNE $2001-$ 2010, iniciou-se o movimento de tramitação do atual Plano Nacional de Educação (PNE), que durou, contudo, quatro anos.

Nesse sentido, o início das disputas pelo atual PNE começaram em dezembro de 2010, com o encaminhamento do Projeto de Lei pelo Poder Executivo ao Congresso Nacional, propondo 20 metas e estratégias, acarretando debates e negociações, envolvendo setores público e privado, recebendo quase três mil emendas em sua fase inicial (DOURADO, 2016).

O processo revelou concepções diversas sobre sociedade e educação, público e privado, qualidade, avaliação, diversidade e regulação (DOURADO, 2016). Nesse contexto, o financiamento da educação, mais uma vez, tornou-se objeto de disputa. Um dos pontos estruturais do Plano Nacional de Educação remete à correlação de forças pelo fundo público, tais como a luta entre os sujeitos que defendem a exclusividade das verbas públicas para a 
A relação conflituosa entre a Meta 20 do Plano Nacional de Educação (2014-2024) e a Emenda Constitucional 95/2016

educação pública e aqueles que defendem que uma extensão dos recursos públicos deve contemplar entidades privadas (DOURADO, 2016).

O atual PNE foi aprovado por meio da Lei 13.005, de 25 de junho de 2014, no auge das disputas eleitorais pelo cargo de presidente da República do Brasil. Com essa Lei, estabeleceram-se diretrizes, metas e estratégias para a educação brasileira, para que se cumprisse o artigo 214 da Constituição Federal de 1988 (DOURADO, 2017).

Ademais, por meio dessa lei, cumpriu-se a exigência constitucional de estabelecer-se uma "meta de aplicação de recursos públicos em educação como proporção do Produto Interno Bruto - PIB, que assegure atendimento às necessidades de expansão, com padrão de qualidade e equidade" (BRASIL, Lei 13.005, 2014, art. 1, VIII). Ou seja, atrelou-se as necessidades educacionais ao tamanho da riqueza do País.

Entre as conquistas da Lei do PNE de 2014, a Meta 20 se configurou um avanço, ao estabelecer a ampliação dos investimentos públicos em educação pública, minimamente, de $7 \%$ do Produto Interno Bruto (PIB) até o quinto ano da Lei e, no mínimo, 10\% do PIB após 10 anos de vigência. Para isso, os entes federativos deveriam se esforçar, principalmente a União, pela sua maior capacidade financeira, para atingir essa meta.

Além disso, de acordo com Dourado (2017), as diretrizes e metas necessitam de condições de gestão, de financiamento e atenção ao PNE como eixo das políticas educacionais. No entanto, o autor também enfatiza que o Brasil tem passado por alterações políticas e econômicas que, talvez, inviabilizem as condições necessárias para implementar o Plano.

Entre essas mudanças, destaca-se o processo de impeachment da Presidente Dilma Rousseff, que contou com o apoio de fração da burguesia brasileira, representada por Deputados e Senadores que pretenderam desrespeitar o processo eleitoral democrático, ao dar prosseguimento ao processo de destituição do cargo maior do Poder Executivo (BOITO JR., 2018). Com isso, o vice-presidente Michel Temer assumiu a presidência da República, compromissado com o Programa de Governo "Uma Ponte para o Futuro".

Esse Programa, elaborado pelo Partido do Movimento Democrático Brasileiro, juntamente com a instituição Ulysses Guimarães, revelou o plano para garantir a conjuntura necessária, tanto no Congresso como no Senado, para aprovar medidas que beneficiassem, principalmente, instituições privadas, face à crise econômico-política do Brasil. Para isso, propuseram a extinção das vinculações constitucionais ${ }^{6}$.

Sob essa demanda, as bases aliadas ao governo em ascensão prosseguiram com a submissão da Proposta de Emenda Constitucional (PEC) para instituir um Novo Regime Fiscal, mediante a Exposição de Motivos Interministerial (EMI) $n^{\circ}$ 00083/2016, protocolado pelo então Ministro da Fazenda, Desenvolvimento e Gestão, Henrique de Campos Meirelles e pelo Ministro Interino do Ministério do Planejamento, Desenvolvimento e Gestão, Dyogo Henrique de Oliveira.

Essa PEC sugeriu um teto para as despesas do governo federal, incluindo os investimentos garantidos pela Constituição Federal na educação e saúde, por serem vistos como a raiz do problema fiscal do governo federal. Na Câmara dos Deputados, PEC 241, no Senado Federal, PEC 55. Apesar da impopularidade da proposta, foi aprovada sob a denominação de Emenda Constitucional (EC) nº 95, de 15 de dezembro de 2016.

6 Garantia legal de recursos públicos para atender a uma finalidade específica. 
A relação conflituosa entre a Meta 20 do Plano Nacional de Educação (2014-2024) e a Emenda Constitucional 95/2016

A EC 95/2016 alterou o Ato das Disposições Constitucionais Transitórias e institui um Novo Regime Fiscal, estabelecendo limites às despesas primárias do governo federal por vinte anos, para serem corrigidas pelo Índice Nacional de Preços ao Consumidor Amplo (IPCA), em outras palavras, determinando um teto orçamentário para cada gasto da União, a ser corrigido pela inflação do ano anterior.

Sendo assim, o investimento na educação, ao ser tratado como despesa primária, foi subjugado às determinações da EC 95/2016, como explica Tanno (2016), ao afirmar que as despesas do governo federal com a educação também são submetidas ao teto de gastos determinados pelo Novo Regime Fiscal. Nesse sentido, a Emenda torna-se um obstáculo para a ampliação de investimento público, conforme garante a Meta 20 do Plano Nacional de Educação, ao determinar um limite para os investimentos na Manutenção e Desenvolvimento do Ensino.

Enquanto o PNE e a própria relação de investimentos públicos em educação com o PIB duraram anos para serem aprovados, a EC 95/2016 durou apenas seis meses para ser promulgada. Isto é, para promover avanços políticos para legislação educacional, leva muito mais tempo que o progresso para a retirada de recursos públicos da educação. O tempo do processo de cada uma dessas leis denota as prioridades dos governos, evidenciando a disputa pelo fundo público no campo das políticas públicas.

Dourado (2016, p. 1) revela que em toda a história educacional do Brasil emergiram disputas políticas "[...] acerca do papel do Estado e do planejamento, da relação entre os entes federados e, como substrato desta, da lógica de organização, gestão e financiamento dos sistemas, de suas redes e instituições". Essa correlação de forças se evidencia no processo de regulação das normas educacionais, particularmente nas políticas de financiamento. Os processos da Lei do PNE e da EC 95 são uma parte dessa história.

Nesse sentido, é possível afirmar que o cenário econômico-político é decisivo para o campo educacional e seu financiamento, e, portanto, para a materialização das metas e estratégias do PNE como plano de Estado (DOURADO, 2016). Assim, é essencial a correlação de forças em busca do avanço das políticas educacionais com vistas ao desenvolvimento de uma sociedade igualitária por meio da educação pública e o devido financiamento, que, em certo momento, conquistou avanços históricos nas últimas décadas, porém hoje ameaçados por políticas governamentais que minam as conquistas sociais.

\section{A materialidade da incompatibilidade da EC com a meta 20 do PNE}

Os dados consolidados sobre os investimentos da União em educação são relevantes, pois podem revelar o compromisso ou descompromisso do governo federal com a Meta 20 da Lei do Plano Nacional de Educação (PNE) de 2014-2024. Nesse sentido, a implementação da Emenda Constitucional (EC) 95/2016 no campo do financiamento da educação poderá agravar a situação do comprometimento, na contramão das necessidades educacionais.

Enquanto o PNE (2014-2024) propõe o aumento progressivo de recursos públicos para a educação pública, de forma que, em um esforço entre os entes federativos, atinja-se $7 \%$ do Produto Interno Bruto (PIB) até o ano de 2019 e, até 2025, no mínimo 10\%, a EC 95/2016 estabelece limites aos gastos do governo federal, incidindo também sobre o aporte de recursos da educação pública.

Nesse contexto, a Emenda 95/2016 estabelece aplicações mínimas em Manutenção e Desenvolvimento do Ensino da União aos níveis das receitas de impostos aplicadas em 2017, 
A relação conflituosa entre a Meta 20 do Plano Nacional de Educação (2014-2024) e a Emenda Constitucional 95/2016

ou seja, impôs um teto para as receitas provenientes de impostos, congelando uma das principais fontes de recursos da União para a educação (TAVARES, 2019).

Dessa forma, as receitas do mínimo constitucional foram congeladas em $\mathrm{R} \$ 48,9$ bilhões, cifras aplicadas em 2017, corrigida pela inflação monetária no ano seguinte, em R\$ 50,4 bilhões (TAVARES, 2019). Nessa situação, as receitas provenientes de impostos, destinadas à Manutenção e Desenvolvimento do Ensino, não crescerão mais conforme a arrecadação, pois encontram-se congeladas (TAVARES, 2019).

O congelamento determinado pela Emenda 95/2016 impede que União, ao ter a maior capacidade financeira de investir em educação pública, colabore com mais intensidade em relação aos demais entes federativos. A Emenda vai de encontro ao artigo 211 da Constituição Federal, que estabelece o regime de colaboração entre os entes federados, com a finalidade de atender os sistemas de ensino.

Com isso, as funções supletiva e distributiva da União, para "[...] garantir equalização de oportunidades educacionais e padrão mínimo de qualidade do ensino mediante assistência técnica e financeira aos Estados, ao Distrito Federal e aos Municípios" (BRASIL, CF 1988, ar. $211, \S 1^{\circ}$ ), ficam menosprezadas. Além disso, com o congelamento dessa receita, a Meta 20 do Plano Nacional de Educação contará com menos recursos.

Revela-se que a Emenda 95/2016 e a Meta 20 do Plano Nacional de Educação (20142014) estabelecem uma relação conflituosa, na qual uma inviabiliza a execução da outra. Para verificar a incongruência entre as leis, expõe-se os dados consolidados da União com Manutenção e Desenvolvimento Ensino, uma vez que a EC 95/2016 impõe suas normas ao governo federal, ou seja, com os dados da tabela a seguir será possível mensurar o compromisso ou o descompromisso desse ente federativo.

Tabela 1 - Todas as receitas e despesas da União com Manutenção e Desenvolvimento do Ensino no período de 2007-2018 (Valores em R \$ milhares, a preços de janeiro de 2019, corrigido pelo IPCA)

\begin{tabular}{c|ccc} 
Exercício & PIB & $\begin{array}{c}\text { Todas receitas e } \\
\text { despesas c/ MDE }\end{array}$ & \% do PIB \\
\hline 2007 & $5.305 .843 .012 .301,40$ & 41.865 .899 .000 & 0,78 \\
2008 & $5.806 .809 .816 .839,10$ & 46.569 .682 .000 & 0,80 \\
2009 & $5.876 .783 .367 .537,30$ & 54.388 .554 .000 & 0,92 \\
2010 & $6.568 .263 .893 .242,10$ & 64.874 .793 .000 & 0,98 \\
2011 & $6.984 .687 .291 .195,60$ & 74.266 .344 .000 & 1,06 \\
2012 & $7.215 .129 .227 .964,00$ & 96.621 .038 .000 & 1,33 \\
2013 & $7.548 .916 .181 .701,10$ & 88.500 .580 .000 & 1,17 \\
2014 & $7.725 .637 .815 .988,10$ & 93.644 .055 .000 & 1,21 \\
2015 & $7.532 .838 .775 .121,10$ & 97.871 .508 .000 & 1,29 \\
2016 & $7.114 .472 .830 .993,50$ & 88.694 .462 .000 & 1,24 \\
2017 & $6.999 .714 .289 .712,40$ & 81.008 .960 .000 & 1,15 \\
2018 & $6.859 .707 .421 .908,00$ & 80.027 .142 .000 & 1,16
\end{tabular}

Fonte: Dados do PIB extraídos do IPEADATA7 , 2019. Correção pelo IPCA realizada no aplicativo Calculadora do cidadão ${ }^{8}$. Dados das receitas e despesas da MDE extraídos do BRASIL/STN/ RREO de 2007 a 2018, corrigidos pelo IPCA. Elaborada pelas autoras.

7 O IPEADATA disponibiliza diversos dados econômicos e financeiros do Brasil em âmbito nacional e regional.

8 A Calculadora do cidadão é uma ferramenta disponibilizada pelo Banco Central do Brasil, com a finalidade de ajudar qualquer cidadão a fazer a correção monetária a partir de diversos índices. 
A relação conflituosa entre a Meta 20 do Plano Nacional de Educação (2014-2024) e a Emenda Constitucional 95/2016

A Tabela 1 demonstra que, entre 2007 a 2018, o Produto Interno Bruto do Brasil (PIB) manifesta uma grande capacidade da União para investimentos em educação. Durante o período analisado, o pico mais alto de investimento ocorreu em 2012. Desde então, as receitas e despesas com Manutenção e Desenvolvimento de Ensino (MDE) têm apresentado constantes retrações em relação ao PIB. Os dados revelam que a União, apesar de ter um poder econômico elevado, investe um pouco mais que $1 \%$ do PIB desde 2011, oscilando, principalmente, negativamente.

Ressalta-se que, para além da capacidade financeira da União, também é imprescindível apresentar a quantidade do alunado em idade educacional de 04 a 17 anos. Essa faixa etária corresponde à idade apropriada para o acesso à educação básica obrigatória e gratuita, conforme prevê o artigo 208 da Constituição Federal. Nesse sentido, apresenta-se a quantidade de alunos nessa faixa etária atendidos no Brasil entre 2007 a 2018 na tabela a seguir:

Tabela 2 - Quantidade de alunos com idade de 4 a 17 anos matriculados no Brasil em 2007-2018

$\begin{array}{lc}\text { Ano } & \text { Quant. de matriculas } \\ \mathbf{2 0 0 7} & 41.292 .278 \\ \mathbf{2 0 0 8} & 42.504 .713 \\ \mathbf{2 0 0 9} & 41.621 .971 \\ \mathbf{2 0 1 0} & 41.918 .175 \\ \mathbf{2 0 1 1} & 41.621 .971 \\ \mathbf{2 0 1 2} & 41.302 .640 \\ \mathbf{2 0 1 3} & 41.295 .194 \\ \mathbf{2 0 1 4} & 40.833 .207 \\ \mathbf{2 0 1 5} & 39.968 .908 \\ \mathbf{2 0 1 6} & 39.842 .727 \\ \mathbf{2 0 1 7} & 39.377 .339 \\ \mathbf{2 0 1 8} & 39.067 .691\end{array}$

Fonte: BRASIL/INEP. Elaborada pelas autoras.

A Tabela 2 demonstra que a quantidade de matrículas de alunos em idade apropriada para a escolarização diminuiu com o passar dos anos. Só em 2018 atingiu a marca de 39 milhões de matrículas. Porém, esses números não refletem a quantidade total de pessoas nessa faixa etária existentes no Brasil. O compromisso do Estado não é apenas com alunos matriculadas em idade apropriada, mas também com pessoas não matriculadas na escola, tanto com as que estão em idade apropriada, quanto com as que, por algum motivo, não puderam frequentar a escola na idade ideal.

Para isso, é necessário um investimento que reflita a realidade educacional. $\mathrm{O}$ aumento de recursos públicos poderia trazer uma série de benefícios para melhorar a qualidade da educação socialmente referenciada. No entanto, se a União, o ente federado que mais arrecada, não intensifica seus investimentos em educação, a qualidade da educação poderá comprometer-se, consequentemente inviabilizando a Meta 20 do Plano Nacional de Educação 2014-2014. Com a implementação da Emenda 95/2016, a situação tende a se aprofundar. Diante da contradição, o financiamento da educação pública torna-se ainda mais sensível às perdas de recursos públicos. 
A relação conflituosa entre a Meta 20 do Plano Nacional de Educação (2014-2024) e a Emenda Constitucional 95/2016

Além desse desafio, outro se faz presente: a divisão de recursos públicos entre instituições públicas e privadas, outra expressão da disputa pelo fundo público. De acordo com o relatório sobre o monitoramento das Metas do PNE, do $1^{\circ}$ Ciclo de Monitoramento das Metas do Plano Nacional de Educação: biênio 2014-2016, publicado pelo Instituto Nacional de Estudos e Pesquisas Educacionais Anísio Teixeira (INEP), com o objetivo de acompanhar o processo de implementação da Meta 20, o investimento público em educação foi analisado sob dois ângulos, 1) o investimento público direto em educação e o 2) investimento público total em educação, conforme a seguir:

O investimento público em educação é analisado sob duas óticas: investimento público direto em educação e investimento público total em educação. $O$ primeiro representa a soma de todos os recursos aplicados pelo setor público (União, estados e municípios) em educação; o segundo engloba, além do investimento público direto, a complementação à aposentadoria futura dos profissionais da educação, os recursos destinados a bolsas de estudos e ao Fundo de Financiamento Estudantil (Fies) e as transferências ao setor privado (BRASIL; INEP, 2016, grifo nosso).

Ou seja, o monitoramento da Meta 20 do PNE efetivou-se de suas formas: a primeira, levando em consideração todos os recursos aplicados em educação por todos os entes federativos, faltando um pouco mais de clareza se esses investimentos se referem apenas aos recursos aplicados em educação pública; a segunda, englobando a primeira forma adicionando-se as aposentadorias dos profissionais da educação mais o Fundo de Financiamento Estudantil (FIES), incluindo as transferências às entidades privadas.

Contudo, de acordo com o Relatório do $1^{\circ}$ Ciclo, o INEP determinou que a segunda forma, o investimento público total em educação, fosse considerada como a oficial, para monitorar o alcance da Meta 20 em 2014, em atendimento às recomendações da Organização para a Cooperação e Desenvolvimento Econômico (OCDE) (BRASIL; INEP, 2018).

A segunda forma já demonstra o desrespeito estatal com o texto da Meta 20, pois a Lei do PNE (2014-2024) prevê o aumento de recursos para a educação pública, não para instituições privadas ou para financiamento dos estudantes. Diante disso, o comparativo entre as duas formas apresenta os seguintes resultados, conforme a Figura 1:

Figura 1 - Investimento Público TOTAL em Educação e Investimento Público DIRETO em Educação de 2004 a 2014

META 20

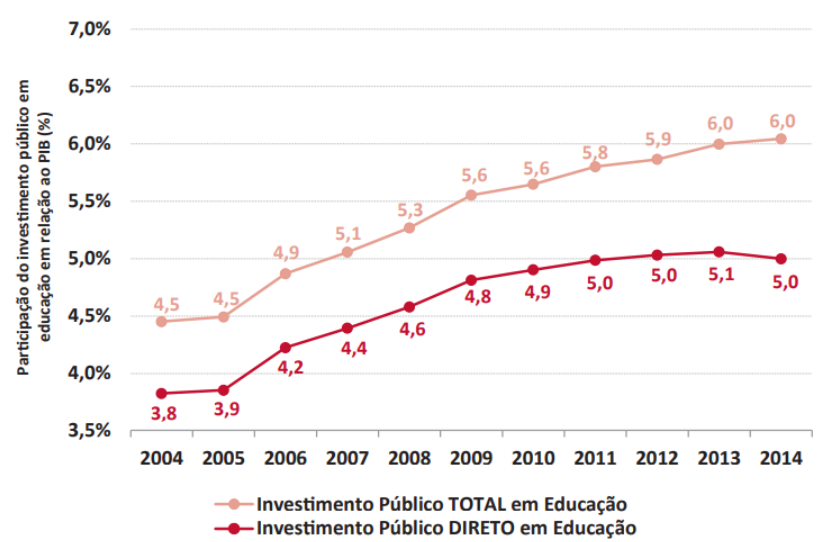

Fonte: BRASIL/INEP. Relatório do $1^{\circ}$ Ciclo DE monitoramento das metas do PNE: biênio 2014-2016, 2016, p. 441. 
A relação conflituosa entre a Meta 20 do Plano Nacional de Educação (2014-2024) e a Emenda Constitucional 95/2016

Ressalta-se que o foco desse relatório era demonstrar, sobretudo, a relação dos investimentos públicos em educação no primeiro ano de vigência do PNE 2014-2024. Ademais, a Figura 1 também revela que a soma dos Investimentos Públicos Totais em Educação tem crescido em média 1 ponto do PIB a cada ano, mantendo-se em 6\% em 2013 e 2014, enquanto o Investimento Direto em Educação tem oscilado para menos, ou mantendo a performance desde 2011.

A Figura 1 também demonstra que os entes federativos gastam menos com Investimento Público Direto em educação do que quando se somam todos os Investimentos Públicos em Educação. Significa afirmar que a concessão de crédito estudantil e os financiamentos de instituições privadas ajudaram a fazer mais volume aos recursos, inclusive aposentadorias ao Investimento Público Total em Educação.

Sob esse panorama, o Relatório do $2^{\circ}$ Ciclo de Monitoramento das Metas do Plano Nacional de Educação - 2018 discorreu sobre a possibilidade de se utilizar essas duas metodologias, por conta da correlação de forças, esclarecendo ainda mais sobre a metodologia de monitoramento empregada. De acordo com o Relatório do $2^{\circ}$ Ciclo, a Lei do PNE 2014-2024 permite essa contradição ao não ser objetiva em uma das duas situações.

A primeira possibilidade metodológica está disposta no artigo 2, inciso VII do PNE, o qual prevê "aplicação de recursos públicos em educação", nesse caso, utilizou-se essa brecha para se contabilizar os recursos que não são investidos na educação pública. A segunda possibilidade está no anexo da Lei, na própria Meta 20, de "ampliar o investimento público em educação pública".

Nesse caso, o INEP considerou os investimentos públicos em educação pública como a seguir:

Atendendo os preceitos da Meta 20, gastos educacionais foram entendidos como todas as despesas necessárias para cumprir o dever do Estado com a educação, conforme as diretrizes elencadas no Art. 208 da Constituição Federal (CF), assim como os gastos em manutenção e desenvolvimento do ensino, definidos no Art. 212 da CF e regulamentados pelo Art. 70 da Lei de Diretrizes e Bases da Educação Nacional de 1996 (Brasil, 1996) (BRASIL; INEP, 2018, p. 326).

Esse trecho manifesta que o dever do Estado com os investimentos na educação pública efetivar-se-á mediante a execução de despesas que atendam às diretrizes elencadas no artigo 208 da Constituição Federal de 1988, considerando que sua obrigação é com a educação básica obrigatória gratuita dos 4 aos 17 anos, inclusive para aqueles que não tiveram acesso à escola nessas idades. Assim, visando sempre a universalização do ensino médio gratuito, do atendimento educacional especializado a pessoas com deficiência na rede regular, da educação infantil, do acesso mais elevado do ensino, tais como a pesquisa e a criação artística, ofertando-se o ensino adequado às condições do aluno, propondo ainda o ensino noturno regular, do atendimento a todos os educando por meio de programas que supram a necessidade de material escolar, transporte, alimentação e assistência à saúde (BRASIL, CF 1988, art. 208, I-VII).

Além disso, o INEP também assume que a educação pública e gratuita contará com recursos elencados no artigo 212 da Constituição Federal, que dizem respeito ao mínimo constitucional proveniente das receitas de impostos, segundo o qual a União tem a obrigação 
A relação conflituosa entre a Meta 20 do Plano Nacional de Educação (2014-2024) e a Emenda Constitucional 95/2016

de aplicar, no mínimo, $18 \%$ das suas receitas liquidas de impostos, e os demais entes federativos devem aplicar, no mínimo, $25 \%$ das suas receitas de impostos.

Ressalta-se que essas receitas apenas serão utilizadas com despesas que executem os objetivos das instituições educacionais, tanto da educação básica, quanto da educação superior, nas seguintes condições:

I - remuneração e aperfeiçoamento do pessoal docente e demais profissionais da educação;

II - aquisição, manutenção, construção e conservação de instalações e equipamentos necessários ao ensino;

III - uso e manutenção de bens e serviços vinculados ao ensino;

IV - levantamentos estatísticos, estudos e pesquisas visando precipuamente ao aprimoramento da qualidade e à expansão do ensino;

V - realização de atividades-meio necessárias ao funcionamento dos sistemas de ensino;

$\mathrm{VI}$ - concessão de bolsas de estudo a alunos de escolas públicas e privadas;

VII - amortização e custeio de operações de crédito destinadas a atender ao disposto nos incisos deste artigo;

VIII - aquisição de material didático-escolar e manutenção de programas de transporte escolar.

Para qualificar os investimentos públicos em educação, o INEP considerou:

Também foram considerados os gastos educacionais enumerados no $\S^{\circ}$ do Art. $5^{\circ}$ do PNE, que abrangem, além dos gastos definidos no Art. 212 da CF, os gastos regulamentados pelo Art. 60 do Ato das Disposições Constitucionais Transitórias relativos ao Fundo de Manutenção e Desenvolvimento da Educação Básica e de Valorização dos Profissionais da Educação (Fundeb), os recursos aplicados nos programas de expansão da educação profissional e superior, inclusive na forma de incentivo e isenção fiscal, as bolsas de estudos concedidas no Brasil e no exterior, os subsídios concedidos em programas de financiamento estudantil e o financiamento de creches, pré-escolas e de educação especial na forma do Art. 213 da CF. Assim, a estimava dos gastos privados determinados nesse parágrafo se restringe aos recursos destinados a instituições que ofertam vagas na educação infantil, especial, profissional e superior. Para contabilizar tais gastos, foram incluídos: 1) subsídios do Programa de Financiamento Estudantil (FIES), 2) gastos tributários e renúncias fiscais concedidas às entidades sem fins lucrativos da educação, às entidades filantrópicas da educação, e às instituições participantes do Programa Universidade para Todos (Prouni) e 3) despesas das entidades privadas de serviço social vinculadas ao sistema sindical (BRASIL; INEP, 2018).

Com isso, constata-se que os interesses públicos e privados se confundem. É uma clara expressão do que vem ocorrendo na história do Brasil, a disputa pelo fundo público. Pela falta de consenso, o Relatório do $2^{\circ}$ Ciclo utilizou as duas metodologias para monitoramento da Meta 20, com a finalidade de mensurar se, em um dos dois casos, o Brasil está cumprindo com o aumento de recursos em relação ao PIB no ano de 2015.

Nesse contexto, por meio do Relatório do $2^{\circ} \mathrm{Ciclo}$, o INEP revelou que o Gasto público em educação pública em proporção ao PIB foi de 5,0\% do PIB em 2015, enquanto o Gasto público em educação foi de 5,5\% em relação ao PIB (BRASIL/INEP, 2018). Com esses dados, é possível afirmar que o compromisso estatal, ou os esforços dos entes federativos, ainda está um pouco distante de alcançar a Meta 20 , de pelo menos $7 \%$ do PIB, até o quinto da Lei do $\mathrm{PNE}$, com os investimentos públicos em educação pública. 
A relação conflituosa entre a Meta 20 do Plano Nacional de Educação (2014-2024) e a Emenda Constitucional 95/2016

Diante da comparação entre os anos de 2014 e 2015, revelou-se o descompromisso estatal com os investimentos em educação pública em relação ao PIB, ao não aumentar o aporte de recursos e ao mantê-lo no mesmo patamar do ano anterior. Retoma-se que o congelamento das receitas de impostos, conforme determina a Emenda Constitucional 95/2016, intensificará ainda mais essa falta de compromisso com os investimentos em educação pública.

\section{Considerações finais}

A luta pelo PNE e pelos investimentos públicos em educação pública relacionados ao PIB são bandeiras levantadas pela sociedade civil organizada, visando uma qualidade educacional socialmente referenciada, que levaram as pautas para o debate político na perspectiva de torná-las Leis, ao contrário do processo da Emenda Constitucional 95/2016, que é uma política implementada e que representa as concepções de uma pequena elite política.

Constatou-se que, quando se trata de garantir recursos para a educação por vias legais, a disputa pelo fundo público mostra-se ainda mais evidente, a exemplo dos resultados do monitoramento da Meta 20 em 2014, quando o INEP utilizou o parâmetro que media recursos públicos aplicados em educação pública e privada relacionados aos $\mathrm{PIB}$, atendendo as recomendações da Organização para a Cooperação e Desenvolvimento Econômico (OCDE).

Em 2015, por conta de reivindicações, o INEP resolveu utilizar duas formas para verificar o cumprimento da Meta 20: a primeira contabilizava todos os investimentos em escolas públicas e privadas, enquanto a segunda contabilizava somente os recursos em educação pública. Em nenhum dos anos os esforços dos entes federativos conseguiram alcançar no mínimo $7 \%$ do PIB.

A Meta 20 do PNE prevê aumento de recursos para a educação pública proporcional ao Produto Interno Bruto (PIB), contudo, no artigo 2, inciso VIII da Lei do PNE, apresenta-se a possibilidade de se contabilizar os recursos públicos aplicados na educação privada. É uma clara expressão de disputa, em que a educação pública está dividindo os escassos recursos públicos com a educação privada.

Além disso, também se revela a disputa de recursos no cerne das políticas públicas voltadas para a educação. Nesse caso, apresenta-se a incompatibilidade entre a Meta 20 do Plano Nacional de Educação (PNE) de 2014 a 2024 e a Emenda Constitucional 95/2016. Respectivamente, uma prevê aumento e a outra determina limites aos gastos públicos. Essa contradição vulnerabiliza ainda mais o financiamento da educação pública e gratuita e impede o avanço previsto em Lei.

\section{Referências}

AMARAL, Nelson Cardoso. Para compreender o financiamento da educação no Brasil. 1. ed. Brasília-DF: Liber Livro Editora, 2012.

BANCO CENTRAL DO BRASIL. Calculadora do Cidadão. Brasília, 2019. Disponível em: $<$ https://www3.bcb.gov.br/CALCIDADAO/publico/exibirFormCorrecaoValores.do?method=exi birFormCorrecaoValores>. Acesso em: 16 maio 2019. 
A relação conflituosa entre a Meta 20 do Plano Nacional de Educação (2014-2024) e a Emenda Constitucional 95/2016

BOITO JR., Armando. Reforma e crise política no Brasil: os conflitos de classe nos governos do PT. São Paulo: Editora Unesp, 2018.

BOLLMAN, Maria Da Graça Nóbrega. Revendo o Plano Nacional De Educação: Proposta da Sociedade Brasileira. Educação \& Sociedade, Campinas, v. 31, n. 112, p. 657-676, jul.-set. 2010. Disponível em: <http://www.scielo.br/pdf/es/v31n112/02.pdf>. Acesso em: 16 maio 2019.

BRASIL. Lei n 4.024, de 20 de dezembro de 1961. Fixa as Diretrizes e Bases da Educação Nacional. Diário Oficial da União, Brasília, DF, 27 dez. 1961. Disponível em: <https://www2.camara.leg.br/legin/fed/lei/1960-1969/lei-4024-20-dezembro-1961-353722publicacaooriginal-1-pl.html>. Acesso em: 30 mar. 2019.

BRASIL. Constituição Federal de 1988. Promulgada em 5 de outubro de 1988. Diário Oficial da União, Brasília, 1988. Disponível: <http://www.planalto.gov.br/ccivil_03/constituicao/cons tituição.htm>. Acesso em: 05 jan. 2017.

BRASIL. Lei $n^{\circ}$ 9.394, de 20 de dezembro de 1996. Estabelece Diretrizes e Bases da Educação Nacional. Diário Oficial da União, Brasília, DF, 23 dez. 1996. Disponível em: <http://www.planalto.gov.br/ccivil_03/leis/l9394.htm>. Acesso em: 03 fev. 2018.

BRASIL. Lei 13.005, de 25 de junho de 2014. Aprova o Plano Nacional de Educação - PNE e dá outras providências. Diário Oficial da União, Brasília, 25 de jun. de 2014 Disponível em: <http://www.planalto.gov.br/ccivil_03/_ato2011-2014/2014/lei//13005.htm>. Acesso em: 02 jan. 2019.

BRASIL. Emenda Constitucional $n^{\circ}$ 95, de 15 de dezembro de 2016. Altera o Ato das Disposições Constitucionais Transitórias, para instituir o Novo Regime Fiscal, e dá outras providências. Diário Oficial da União, Brasília, DF, 15 dez. 2016. Disponível em: <http://www.planalto.gov.br/ccivil_03/constituicao/emendas/emc/emc95.htm>. Acesso: 06 jan. 2018.

BRASIL. Instituto Nacional de Estudos e Pesquisas Educacionais Anísio Teixeira. Relatório do $1^{\circ}$ ciclo de monitoramento das metas do PNE: biênio 2014- 2016. Brasília, DF: Inep, 2016. Disponível em: <http://pne.mec.gov.br/publicacoes/item/download/14_7bbc6c42 93beeac1fd963c16d935f40>. Acesso em: 17 maio 2019.

BRASIL. Instituto Nacional de Estudos e Pesquisas Educacionais Anísio Teixeira. Relatório do $2^{\circ}$ Ciclo de Monitoramento das Metas do Plano Nacional da Educação - 2018. Brasília, DF: Inep, 2018. Disponível em: <http://pne.mec.gov.br/publicacoes/item/down load/15_43f943e1c8b9aaf756af3875d8561a10>. Acesso em: 17 maio 2019.

BRASIL. Instituto Nacional de Estudos e Pesquisas Educacionais Anísio Teixeira. Sinopse Estatística da Educação básica 2007 a 2018. Brasil: Inep, 2019. Disponível em: $<$ http://inep.gov.br/web/guest/sinopses-estatisticas-da-educacao-basica>. Acesso em: 01 maio 2019.

BRASIL. Subchefia de Assuntos Parlamentares. Exposição de Motivos Internos - EMI $\mathbf{n}^{\circ}$ 00083/2016 - Carta de Submissão da Proposta de Emenda Constitucional para um Novo Regime Fiscal. Ministério da Fazenda - MF e Ministério do Planejamento e Desenvolvimento e Gestão - MPDG. Brasília: MF/MPDG, 2016. Disponível em: 
A relação conflituosa entre a Meta 20 do Plano Nacional de Educação (2014-2024) e a Emenda Constitucional 95/2016

<http://www.planalto.gov.br/ccivil_03/Projetos/ExpMotiv/EMI/2016/83.htm>. Acesso em: 17 fev.2018.

BRASIL. Tesouro Nacional. Relatório Resumido da Execução Orçamentária do Governo Federal e Outros Demonstrativos. Brasília: DF, dez. 2017-2018.

DOURADO, Luiz Fernando. Plano Nacional de Educação: Política de Estado para a Educação Brasileira. Brasília: Inep, 2016. Disponível em: <http://portal.i nep.gov.br/documents/186968/523064/PLANO+NACIONAL+DE+EDUCA\%C3\%87\%C3\%83 O+-+Pol\%C3\%ADtica+de+Estado+para+a+educa\%C3\%A7\%C3\%A3o+brasileira/2cbb3d59497d-45a8-a5af-d3bbe814336e?version=1.5>. Acesso em 14 abr. 2019.

DOURADO, Luiz Fernando. PNE 2014/2014: Avaliações e perspectivas de um plano de Estado. In: DOURADO, Luiz Fernandes (Org.). Plano nacional de educação - PNE 2014/2024: Avaliação e perspectivas. Campinas: Mercado de Letras, 2017.

HELENE, Otaviano. Um diagnóstico da educação brasileira e de seu financiamento. Campinas: Autores Associados, 2013.

IPEADATA. Instituto de Pesquisa Econômica Aplicada. Série do Produto Interno Bruto. Brasília: Ipea, 2019. Disponível em: <http://www.ipeadata.gov.br/Default.aspx>. Acesso em 14 jan. 2019.

PMDB. Partido do Movimento Democrático Brasileiro. Uma Ponte para o Futuro. Brasília: Fundação Ulysses Guimarães, 2015. Disponível em: $<$ https://www.fundacaoulysses.org.br/wp-content/uploads/2016/11/UMA-PONTE-PARAOFUTURO.pdf>. Acesso em: 20 mar. 2019.

SALVADOR, Evilasio. Financiamento tributário da política social no pós-real. In: SALVADOR, Evilasio et al. (Org.). Financeirização, Fundo Público e Política Social. São Paulo: Cortez, 2012. p. 123-152.

SAVIANI, Dermeval. Sistemas de ensino e planos de educação: O âmbito dos municípios. Educação \& Sociedade, Campinas, ano XX, n. 69, dez. 1999. Disponível em: <http://www.scielo.br/pdf/es/v20n69/a06v2069.pdf>. Acesso em: 01 abr. 2019.

SAVIANI, Dermeval. Sistema Nacional de Educação articulado ao Plano Nacional de Educação. Revista Brasileira de Educação, Rio de Janeiro, v. 15, n. 44, p. 380-412, maio/ago. 2010.

TANNO, Cláudio Riyudi. Orçamento da Educação: Riscos de compressão das despesas não asseguradas pela PEC N² 241/2016. Estudo Técnico ${ }^{\circ}$ 22/2016 - CONOF / CD. out. 2016. Disponível: <http://www2.camara.leg.br/orcamento-dauniao/estudos/2016/EstudoTcnicon1 22016versao21ago_publicado.pdf>. Acesso em 21 jun. 2018.

TAVARES, Darlyng Maria Gomes. Emenda Constitucional 95/2016: Instrumento de retomada da desvinculação das receitas da União sobre a Manutenção e Desenvolvimento do Ensino. 2019. Dissertação (Mestrado em Educação) - Faculdade de Educação, Universidade Federal do Amazonas, Manaus, 2019.

VIEIRA, Jairo José; RAMALHO, Carla Chagas; VIEIRA, Andréa Lopes da Costa. A origem do Plano Nacional de Educação e como ele abordou as questões de gênero. RPGE - Revista 
A relação conflituosa entre a Meta 20 do Plano Nacional de Educação (2014-2024) e a Emenda Constitucional 95/2016

online de Política e Gestão Educacional, v. 21, n. 1, p. 64-80, 2017. Disponível em: <https://periodicos.fclar.unesp.br/rpge/article/view/9746>. Acesso em: 17 maio 2019.

Silvia Cristina Conde Nogueira é graduada em Pedagogia (2001), Mestra (2007) e Doutora (2016) em Educação pela Universidade Federal do Amazonas (UFAM). Desde 2009 é professora na UFAM, onde atua no Departamento de Administração e Planejamento (DAPLAN) e no Programa de Pós-Graduação em Educação (PPGE) da Faculdade de Educação (FACED). Atualmente é Diretora da FACED, eleita para o quadriênio 2018-2022. ORCID: http://orcid.org/0000-0001-6800-5615

E-mail: silviaconde@uol.com.br

Darlyng Maria Gomes Tavares é mestra em Educação pelo Programa de Pós-graduação em Educação pela Universidade Federal do Amazonas (2019) e licenciada em Pedagogia pela Universidade Federal do Amazonas (2017).

ORCID: http://orcid.org/0000-0003-2521-5174

E-mail: darlyng.tavares.dt@gmail.com 


\section{Editores do volume 10}

Márcia Aparecida Jacomini - Universidade Federal de São Paulo, Brasil

José Marcelino de Rezende Pinto - Universidade de São Paulo, Brasil

\section{Comitê Editorial}

Nalú Farenzena - Universidade Federal do Rio Grande do Sul, Brasil

Juca Gil - Universidade Federal do Rio Grande do Sul, Brasil

Theresa Adrião - Universidade Estadual de Campinas, Brasil

Ângelo Ricardo de Souza - Universidade Federal do Paraná, Brasil

\section{Conselho Editorial}

\section{Alejandro Morduchowicz}

Universidad Pedagógica, Provincia de Buenos Aires, Argentina

Andréa Barbosa Gouveia

Universidade Federal do Paraná, Brasil

Fernanda Saforcada

Universidade de Buenos Aires, Argentina

Jacques Velloso

Universidade de Brasília, Brasil

João Monlevade

Senado Federal, Brasil

Jorge Abrahão de Castro

Instituto de Pesquisa Econômica Aplicada / IPEA, Brasil

Lisete Regina Gomes Arelaro

Universidade de São Paulo, Brasil

Luis Carlos Sales

Universidade Federal do Piauí, Brasil

Luiz de Sousa Junior

Universidade Federal da Paraíba, Brasil

Luiz Fernandes Dourado

Universidade Federal de Goiás, Brasil

Magna França

Universidade Federal do Rio Grande do Norte, Brasil

Marcos Edgar Bassi

Universidade Federal de Santa Catarina, Brasil

Maria Angélica Pedra Minhoto

Universidade Federal de São Paulo, Brasil

Maria Beatriz Luce

Universidade Federal do Rio Grande do Sul, Brasil

Maria Dilnéia Espíndola Fernandes

Universidade Federal de Mato Grosso do Sul, Brasil

Nelson Cardoso do Amaral

Universidade Federal de Goiás, Brasil

Nicholas Davies

Universidade Federal Fluminense, Brasil

Robert E. Verhine

Universidade Federal da Bahia, Brasil

Romualdo Portela de Oliveira

Universidade de São Paulo, Brasil

Rosana Gemaque Rolim

Universidade Federal do Pará, Brasil

Rubens Barbosa de Camargo

Universidade de São Paulo, Brasil

Theresa Adrião

Universidade Estadual de Campinas, Brasil

Tristan McCowan

University of London, Reino Unido

Vera Jacob

Universidade Federal do Pará, Brasil

Vera Peroni

Universidade Federal do Rio Grande do Sul, Brasil

Vitor Henrique Paro

Universidade de São Paulo, Brasil

\section{Equipe editorial}

Apoio ao Comitê Editorial: Caio Cabral da Silva

Diagramação, Revisão de português e normalização: Edson Leonel de Oliveira

Revisão de inglês: Sabrina Ferreira

Fineduca - Revista de Financiamento da Educação

Associação Nacional de Pesquisa em

Financiamento da Educação

e-mail: revista.fineduca@gmail.com | site: http://seer.ufrgs.br/fineduca 